SLAC-TN-10-039

LCLS-TN-08-4

\title{
Magnetic Measurements of the Background field in the Undulator Hall With Ductwork and Cable Trays
}

\author{
Andrew Fisher, Heinz-Dieter Nuhn, James Welch
}

$3 / 27 / 2008$

\begin{abstract}
The duct work and cable trays present in the undulator hall facility are made out of potentially magnetically active materials. This note describes a measurement done to make a comparison between the fields in the undulator hall with the duct work and cable trays present and in the Magnetic Measurement Facility.
\end{abstract}

\section{1. Introduction ${ }^{1}$}

In order for the undulators to have the proper tuning, the background magnetic field in the Undulator Hall must agree with the background field in the Magnetic Measurements Facility within 0.5 gauss.

To verify that this was the case, measurements were taken along the length of the undulator hall, and the point measurements were compared to the mean field which was measured on the MMF test bench. This set of measurements was conducted with most of the cable trays and duct work in place, but without any of the magnet stands in place.

\section{2. Test Setup}

The device used to measure the magnetic fields in the tunnel was a Barrington Instruments MAG-03 3 axis Fluxgate probe with a range of -5 to 5 gauss. The measurements were completed at an interval of approximately 12 meters apart down the length of the undulator hall using the floor monuments as references. The device was aligned so that the $\mathrm{Z}$ of the probe pointed appoximately in

\footnotetext{
${ }^{1}$ Work supported in part by the DOE Contract DE-AC02-76SF00515. This work was performed in support of the LCLS project at SLAC.
} 
the direction of the beam, the $\mathrm{Y}$ direction at the ceiling, and the $\mathrm{X}$ direction at the north wall of the tunnel. All measurements were taken at a height of approximately 1.4 meters off of the floor of the undulator hall. The $\mathrm{X}$ position was fixed using a tape measure measurement from the floor monument.

\section{3. Data And Conclusions}

The measurements of the field were similar to previous measurements but with some key differences. The large scale measurements of the hall were similar to the measurements taken during the last test without the cable trays and temperature control systems. On the previous set of measurements there was not found to be any small scale structure in the tunnel, either in $\mathrm{X}$ or $\mathrm{Z}$, but with the new equipment in place, some smaller scale structure was induced. In $\mathrm{X}$ there appears to be structure caused by shielding due to the steel content of the cable trays and ductwork. 


\section{4. Plots and Photos}

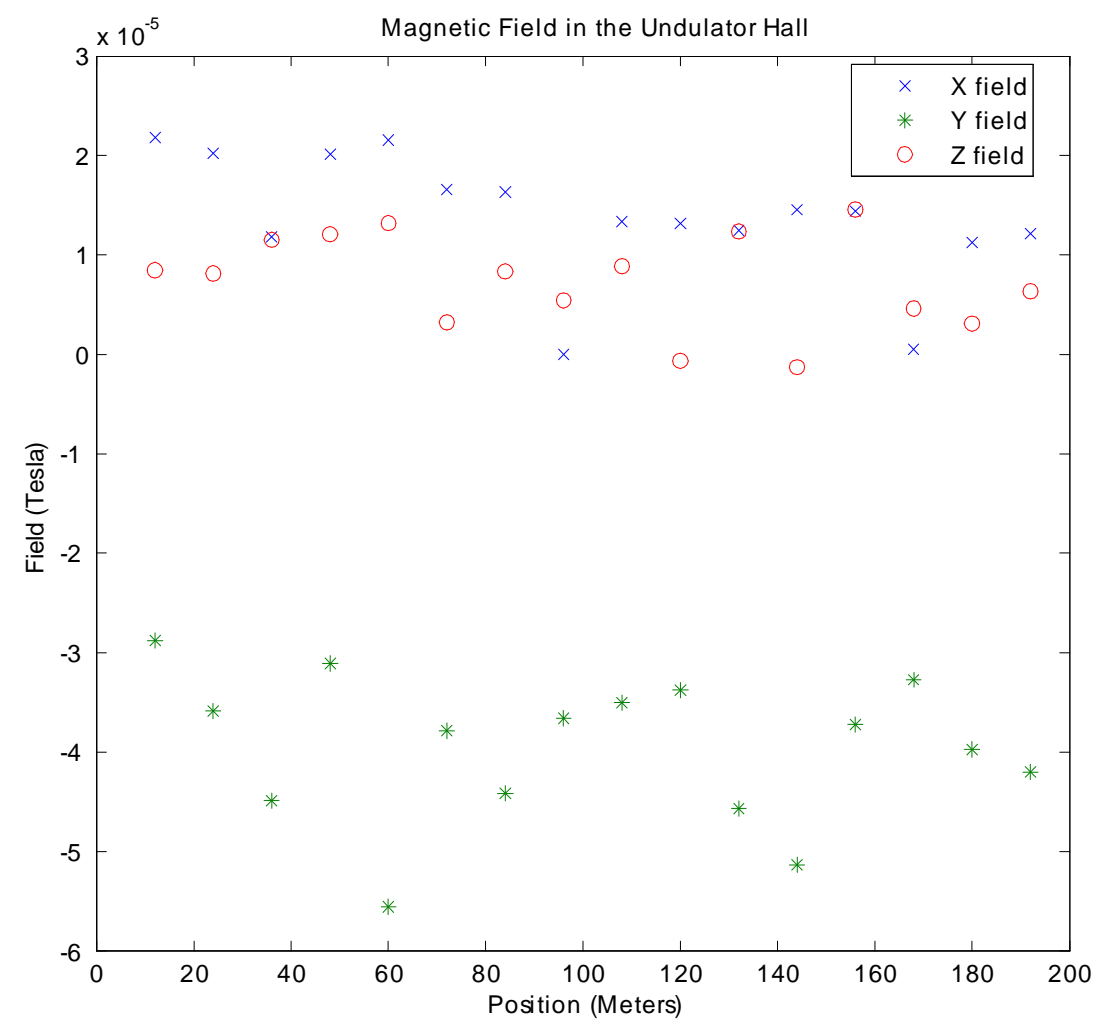

Figure 1: Raw magnetic field in the undulator hall measured in tesla 


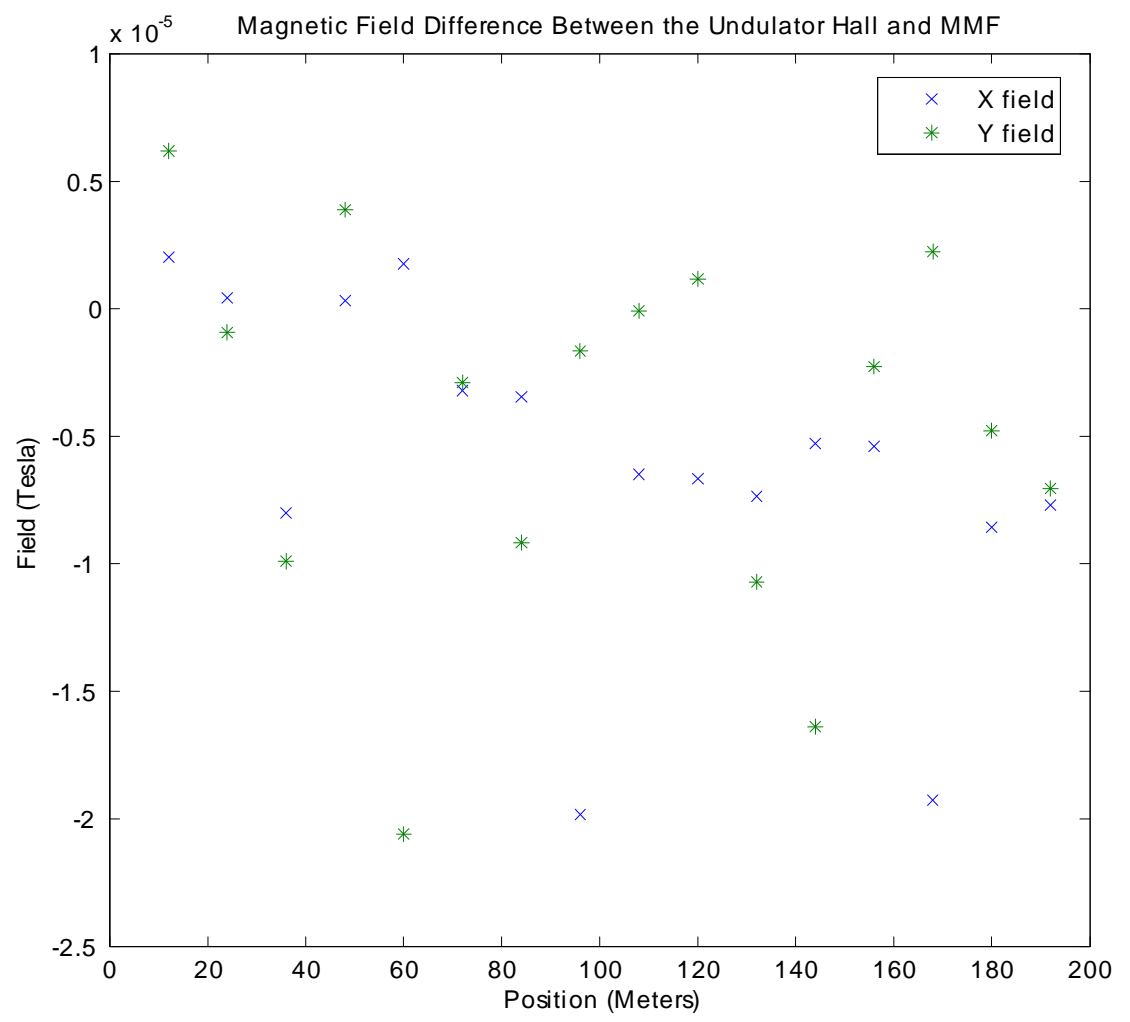

Figure 2: Comparison of the $\mathrm{x}$ and $\mathrm{y}$ field in the Magnetic Measurement Facility and the Undulator Hall 


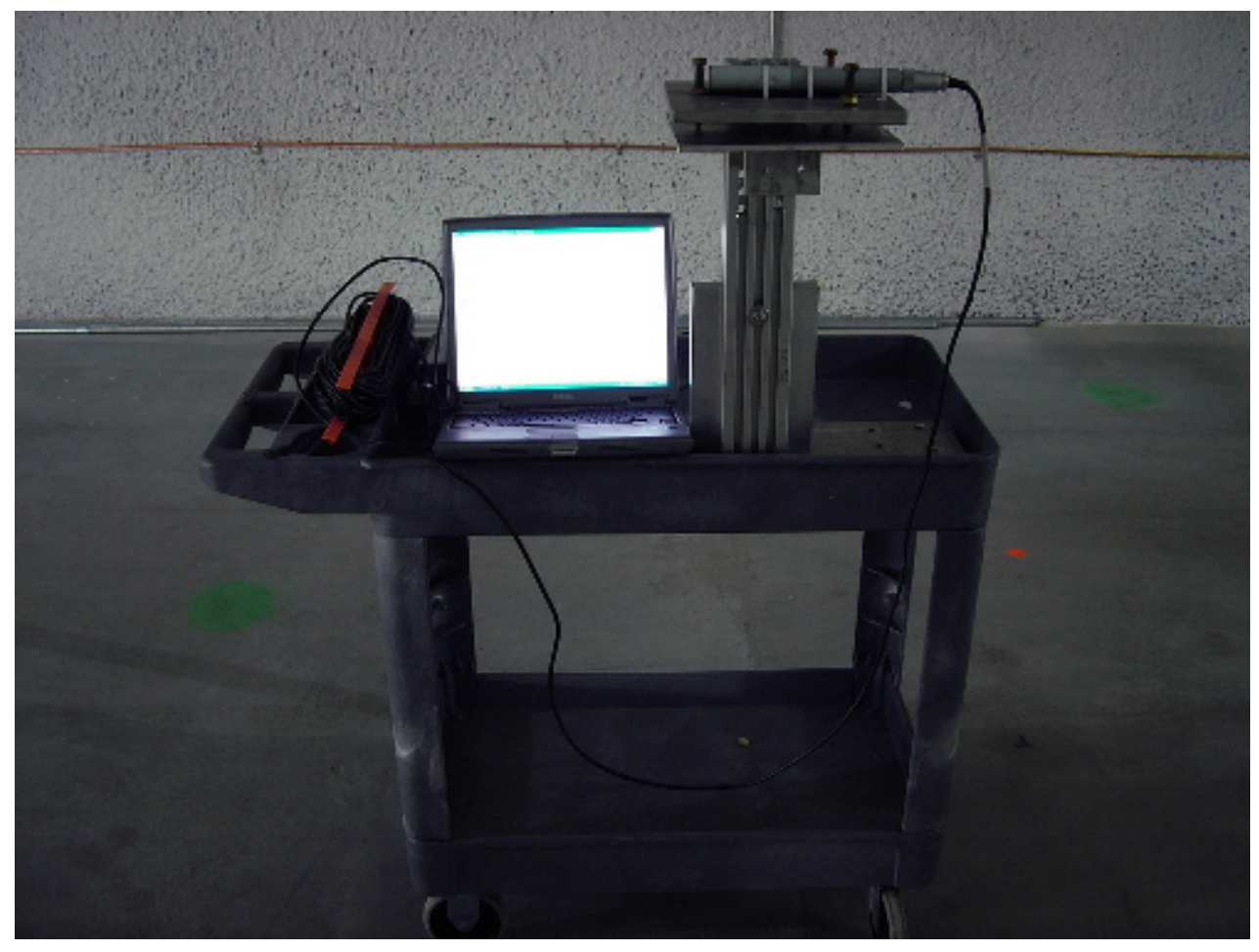

Figure 3: Apparatus for using a fluxgate probe to measure the fields 


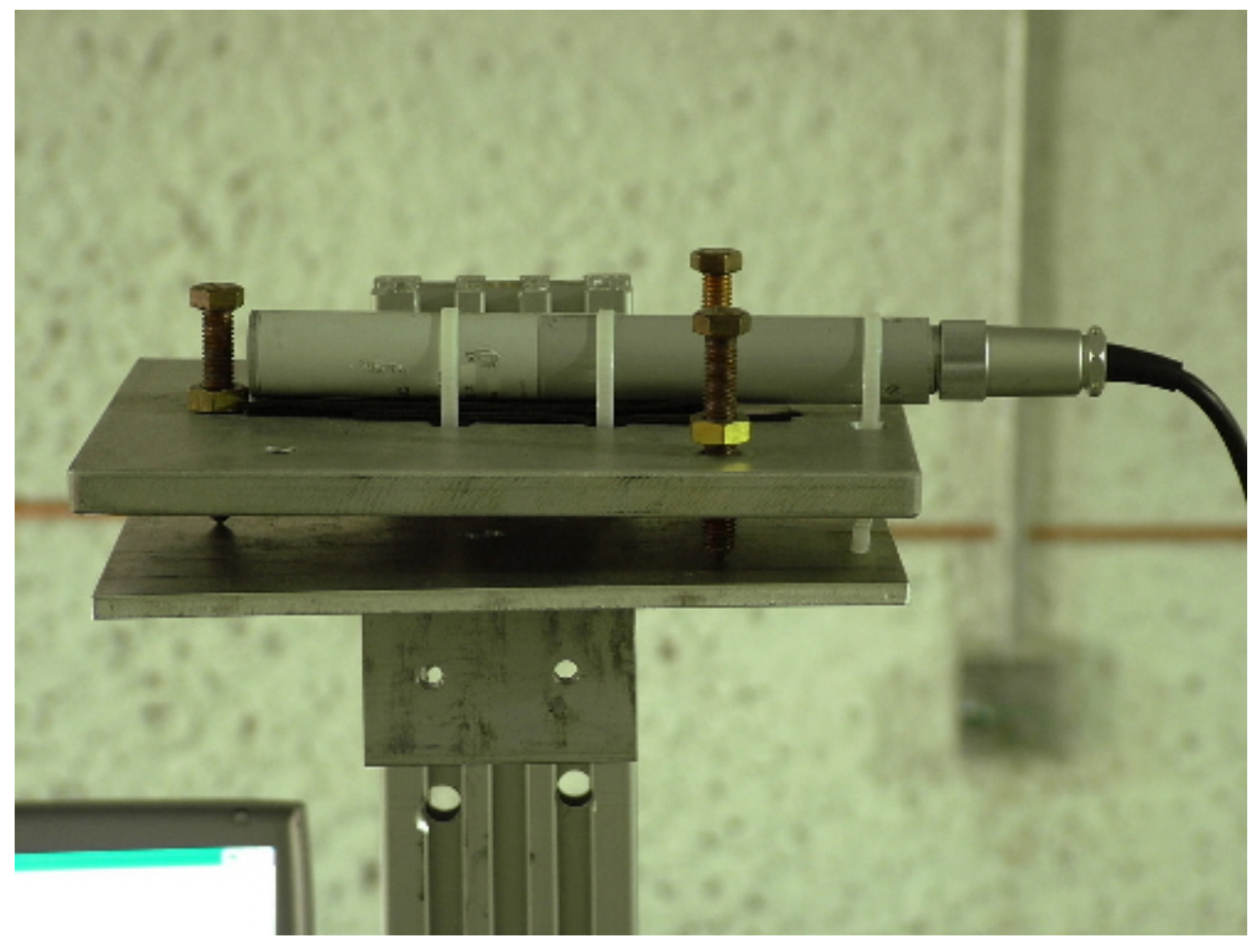

Figure 4: Close up of 3 Axis fluxgate probe 


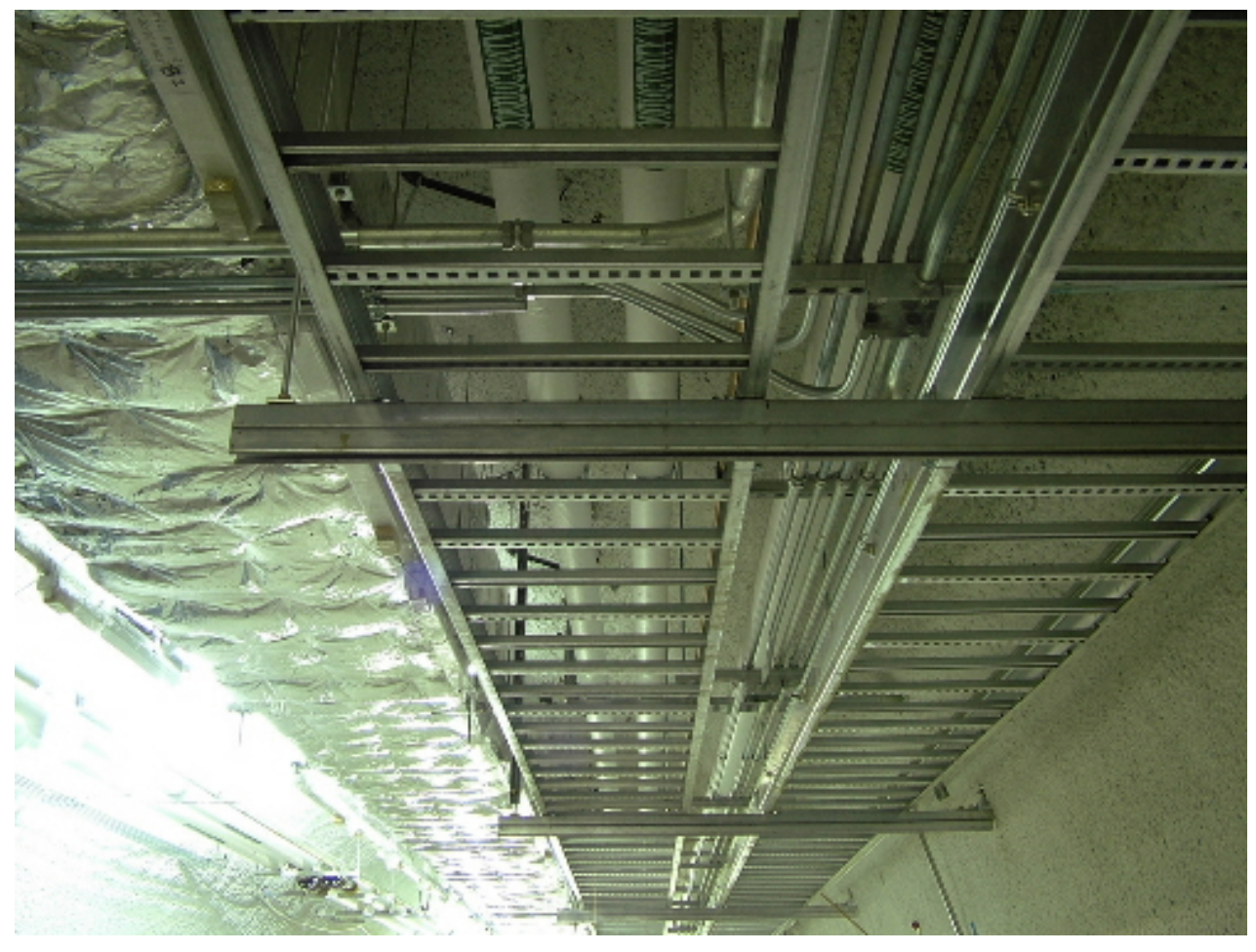

Figure 5: Ducting and cable trays 